\title{
Growth Inhibition by Caffeic Acid, One of the Phenolic Constituents of Honey, in HCT 15 Colon Cancer Cells
}

\author{
Saravana Kumar Jaganathan \\ Department of Biomedical Engineering, PSNA College of Engineering and Technology, \\ Dindugal, Kothandaraman Nagar, Dindugal 624622, Tamil Nadu, India \\ Correspondence should be addressed to Saravana Kumar Jaganathan, jaganathaniitkgp@gmail.com
}

Received 11 October 2011; Accepted 21 November 2011

Academic Editors: S. Cuzzocrea and S. K. Ray

Copyright ( 92012 Saravana Kumar Jaganathan. This is an open access article distributed under the Creative Commons Attribution License, which permits unrestricted use, distribution, and reproduction in any medium, provided the original work is properly cited.

\begin{abstract}
Previous work from our laboratory showed that the mechanism of crude-honey induced apoptosis in colon cancer cells. Since phenolic constituents of honey were attributed to its apoptosis-inducing ability, we studied caffeic acid, one of the phenolic constituents of honey, induced effect on colon cancer cells. Antiproliferative effect of caffeic acid was estimated using 3-(4,5dimethylthiazol-2-yl)-2,5-diphenyl tetrazolium bromide (MTT) assay. MTT assay signified the antiproliferative nature of caffeic acid against the HCT 15 colon cancer cells. A time-dependent inhibition of colony formation was evident with caffeic acid treatment. Cell-cycle analysis of caffeic acid- (CA-) treated cells indicated increasing accumulation of cells at sub- $\mathrm{G}_{1}$ phase. Photomicrograph images of treated cells showed membrane blebbing and cell shrinkage. Yo-pro-1 staining of caffeic-acid-treated cells confirmed apoptosis in dose- and time-dependent manner. Increasing ROS generation and reduction in the mitochondrial membrane potential were also accompanied in the caffeic acid-induced apoptosis. This work will promote caffeic acid as a likely candidate in the chemoprevention of colon cancer.
\end{abstract}

\section{Introduction}

Recent surveys indicated colorectal cancer as one of the most common and lethal cancers in Western states [1]. This cancer now paved entry into the Asian nations because of the people desire for Western diet which is growing rapidly. Although various conventional treatments exist, they still remain insufficient to eradicate this disease. Hence, the search for novel anticancer agents with better versatility in improving the disease condition is constantly increasing.

Previous work from our laboratory showed that honey could induce apoptosis in colon cancer cells. The apoptosis inducing potential of honey varied among the cell lines. On the basis of its total phenolic content, honey-induced apoptosis varied among the different honey types. Honey possessing higher phenolic content could inhibit the growth of colon cancer cells significantly $[2,3]$. Hence, we extended our research to study the effect of caffeic acid, one of the most commonly reported phenolic constituent of honey, in colon cancer cells.
Caffeic acid is also widely found in coffee, fruits and vegetables [4]. It possesses both antioxidant and antitumor potential $[5,6]$. Caffeic acid protected human KF1 diploid fibroblast and A431 epidermoid carcinoma cell lines from UVC-induced cytotoxicity [7]. It was shown to inhibit UVB $(280-320 \mathrm{~nm})$ radiation-induced IL-10 expression and the activation of the mitogen-activated protein kinases (MAPKs) in mouse skin [8]. In a recent work, it was shown caffeic acid inhibited the cell proliferation of HepG2 cells in a dose-dependent manner. It blocked the MMP-9 expression by inhibiting the NF- $\kappa$ B activity. Finally, they showed that caffeic acid at a dose of $20 \mathrm{mg} / \mathrm{kg}$ retarded the growth of HepG2 tumor xenografts in immunosuppressive mice [9]. Caffeic acid was shown to inhibit the growth of HT 29 colon cancer cells. Caffeic acid at a concentration of $2500 \mu \mathrm{M}$ found to inhibit $50 \%$ cell proliferation of HT 29 cells [10]. However, no further work was initiated about the apoptosis induced by caffeic acid in colon cancer cells. Therefore, it is worthy to investigate the mechanism of caffeic-acid-induced apoptosis in colon cancer cells. 
Programmed cell death or apoptosis is a major form of self destructive internally engineered cell death. It is complemented with diverse morphological changes like formation of membrane blebs, chromatin and nuclear condensation, segregation of apoptotic bodies, and DNA fragmentation. Reactive oxygen species (ROS) plays a pivotal role in various biochemical functions like cell proliferation and apoptosis. Many studies reported that ROS-mediated apoptosis is accompanied with the loss of mitochondrial membrane potential $[11,12]$.

In this present study, we aimed to examine the apoptotic nature of caffeic acid in colon cancer cells. Further we tried to explore the ROS and mitochondrial dependent mechanism in the apoptosis induced by the caffeic acid.

\section{Materials and Methods}

2.1. Reagents. RPMI 1640, fetal bovine serum (FBS), Lglutamine, sodium pyruvate, nonessential amino acids, vitamin solution, penicillin, and streptomycin were obtained from Life Technologies, Inc., Grand Island, NY, USA. 3-(4,5dimethylthiazol-2-yl)-2,5-diphenyl-tertazolium-bromide (MTT), Propidium Iodide (PI), Rhodamine 123, RNase, and caffeic acid were purchased from Sigma-Aldrich, USA. YO-PRO-1 was obtained from Invitrogen Inc. USA.

2.2. Cell Culture. Colon carcinoma cell line HCT 15 (Organ: Colon, Disease: Colorectal adenocarcinoma; Organism: Human; procured from National Centre for Cell science (NCCS), Pune, India) was grown in RPMI medium supplemented with 10\% FBS, L-glutamine, penicillin, sodium pyruvate, nonessential amino acids, and vitamin solution. Adherent monolayer cultures were maintained in T-25 flasks and incubated at $37^{\circ} \mathrm{C}$ in $5 \%$ carbon dioxide $\left(\mathrm{CO}_{2}\right)$. The cultures were free of mycoplasma and maintained no longer than 12 weeks after recovery from frozen stocks.

2.3. Cell Proliferation Assay (MTT Assay). Thiazolyl blue tetrazolium bromide (MTT) assay was carried out as follows. Cells were trypsinized and counted, and 1000 cells were seeded per well in 96-well plate. The following day, $100 \mu \mathrm{L}$ of medium containing the desired concentration of caffeic acid was added to the appropriate wells. The cells were then kept at $37^{\circ} \mathrm{C}$ in $5 \% \mathrm{CO}_{2}$ for the desired length of time. Control used in these experiments was untreated cells kept for $48 \mathrm{~h}$. For all the experiments performed below, control cells remained untreated and kept for the same duration as the longest time point of the respective experiment. At this point, $100 \mu \mathrm{L}$ of $(5 \mathrm{mg} / \mathrm{mL})$ MTT reagent was added to each well and the plate was placed at $37^{\circ} \mathrm{C}$ in the incubator for 2 h. $200 \mu \mathrm{L}$ of dimethyl sulfoxide was added to each well after aspirating the supernatant. Colored formazan product was assayed spectrophotometrically at $570 \mathrm{~nm}$ using ELISA plate reader [13].

2.4. Colony Forming Assay. HCT 15 cells were treated with caffeic acid $\left(\mathrm{IC}_{50}\right.$ concentration estimated from MTT assay $(800 \mu \mathrm{M})$ was used for all experiments unless otherwise stated) for definite time periods (12, 24, and $48 \mathrm{~h}$ ) and collected by trypsinization. The cells were counted and seeded again in triplicate on a 6-well tissue culture plate with 3000 cells/well. The cells were cultured for 15 days with growth media replaced after every two days. The cells were stained with $0.5 \%$ crystal violet (in methanol) and colonies were counted [14].

\subsection{Relative Cellular Size and Granularity and Photomicro-} graph Images. Changes to the relative size and granularity of caffeic-acid-treated colon cancer cells were determined using flow cytometric analysis of forward and side laser light scatter characteristics. Further photomicrograph images of treated cells were acquired [13].

2.6. Cell-Cycle Analysis. After the appropriate treatment with caffeic acid, cells were washed with phosphate-buffered saline then resuspended in $50 \mu \mathrm{g} / \mathrm{mL}$ propidium iodide containing $0.1 \%$ sodium citrate with $0.1 \%$ Triton X-100 for $20 \mathrm{~min}$ at $4^{\circ} \mathrm{C}$. Cells were then analyzed by flow cytometry (FACScan; Becton Dickinson Immunocytometry Systems), and the sub$\mathrm{G}_{1}$ fraction was used as a measure of the apoptotic cells. Control used in the experiments was untreated cells kept for $48 \mathrm{~h}$. Analysis was performed in linear amplification mode in case of cell-cycle analysis. Remaining experiments of flow cytometry were performed in logarithmic amplification mode unless otherwise stated [13].

2.7. Estimation of ROS Generation. $2^{\prime}, 7^{\prime}$-dichlorofluorescin diacetate (DCFH-DA) was cleaved by the intracellular nonspecific esterase to form DCFH. DCFH are oxidized by ROS to form the fluorescent compound DCF. Caffeic-acid-treated cells were harvested using Trypsin/EDTA and resuspended in PBS. Working solution $(20 \mu \mathrm{M})$ of DCFH-DA was directly added to cells, and then, it was incubated at $37^{\circ} \mathrm{C}$ for 15 minutes. Cells were washed and resuspended in PBS and kept on ice immediately before analyzing by flow cytometry [13]. This fluorescent intensity of DCF was measured and correlated with the ROS generated in the cells.

2.8. Determination of Mitochondrial Membrane Potential. HCT 15 colon cancer cells were treated with caffeic acid for different time points. Afterwards, cells were harvested and resuspended in $1 \mathrm{~mL}$ of rhodamine $123(5 \mu \mathrm{g} / \mathrm{mL})$ for $1 \mathrm{~h}$ at $37^{\circ} \mathrm{C}$. The intensity of fluorescence from rhodamine 123 was measured by flow cytometry [13].

2.9. YO-PRO-1 Staining. YO-PRO-1 iodide permits analysis of apoptotic cells without interfering cell viability. After treatment, the cell pellets were mixed in $1 \mu \mathrm{M}$ YO-PRO1 for $20 \mathrm{~min}$ at room temperature before flow cytometric measurements [13].

2.10. Statistical Analyses. All values are expressed as the mean \pm standard deviation. Figures were plotted with standard error using OriginPro 7.5 software. 


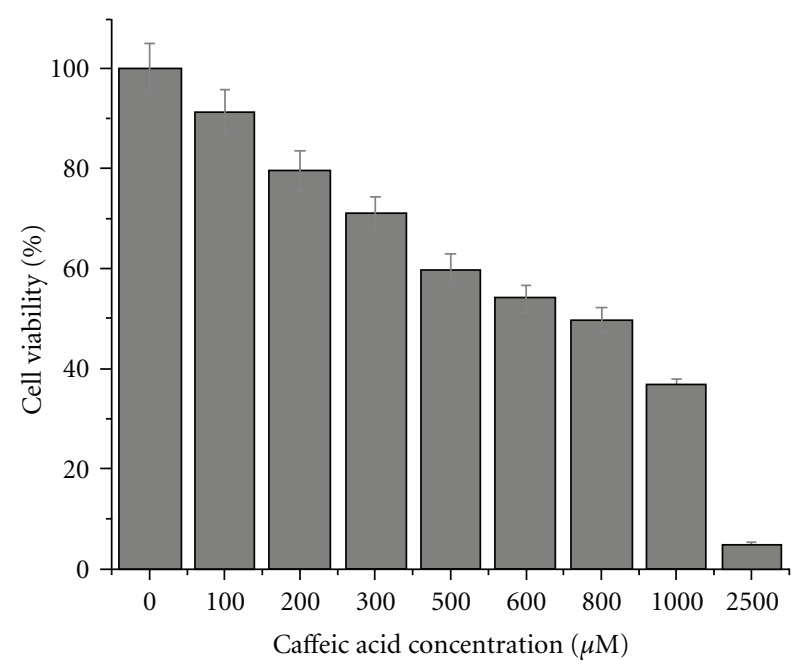

(a)

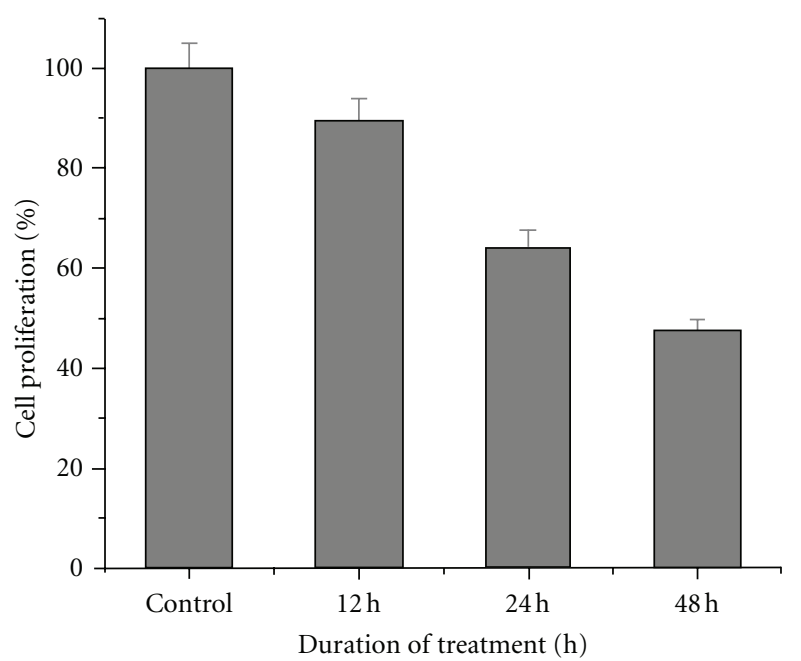

(b)

FIgURe 1: Antiproliferative effect of caffeic acid against colon cancer cells growth in vitro. (a) HCT 15 cells grown in 96-well plates were treated with various concentrations of caffeic acid diluted in the RPMI media for $48 \mathrm{~h}$. The mean of the percentage cell viability (\% of untreated HCT 15 cells) along with their standard error is indicated. (b) After various incubation periods of caffeic acid treatment, colonies formed were stained with $0.5 \%$ crystal violet and counted, and percentage of survival was calculated. Data reported as the mean \pm SE from three different observations. Means are significant at 24 and $48 \mathrm{~h}(P<0.05)$.

\section{Results}

3.1. Cell Proliferation Assay. MTT assay was used to assess the antiproliferative effect of caffeic acid. Logarithmically grown HCT 15 cells were treated with varying concentration of caffeic acid for $48 \mathrm{~h}$. Caffeic acid inhibited the growth of HCT 15 cells in a dose-dependent manner (Figure 1(a)). HCT 15 cell growth were repressed significantly with an $\mathrm{IC}_{50}\left(\mathrm{IC}_{50}\right.$ : percentage at which $50 \%$ cells were dead approximately) of $800 \mu \mathrm{M}$. We used $\mathrm{IC}_{50}$ concentration of caffeic acid for all our subsequent experiments unless stated otherwise.

3.2. Colony Forming Assay. Colony forming assay was used to assess the colony forming ability of caffeic-acid-treated cells. Untreated HCT 15 cells produced with an average mean of 95 colonies. Caffeic-acid-treated cells showed an average of $85,61,45$ colonies after 12,24 , and 48 h of treatment. A timedependent inhibition of colony formation was clearly evident from this experiment (Figure 1(b)).

\subsection{Relative Cellular Size and Granularity and Photomicro-} graph Images. Generally apoptotic cells show a decreased relative size and increased internal complexity. Caffeic acid treated cells showed a decrease in the mean forward scatter and an increase in mean side scatter (Figure 2(a)) in a timedependent manner while comparing with the untreated cells grown for $48 \mathrm{~h}$. This may be attributed to the apoptosis induced by caffeic acid. Moreover, photomicrograph images of caffeic acid treated cells showed membrane blebbing and shrinkage of cells depicting apoptosis (Figure 2(b)).

3.4. Cell-Cycle Analysis. Cell-cycle analysis of caffeic-acid treated cells was performed using PI staining. Both dose- and time-dependent relationship of caffeic-acid-treated HCT 15 cells were examined. Dose-dependent analysis of 500, 1000 and $2000 \mu \mathrm{M}$ of caffeic acid showed an increasing sub- $\mathrm{G}_{1}$ arrest of 11.61, 28.27, and 33.10, respectively. Untreated control cells showed only $1.71 \%$ of sub- $\mathrm{G}_{1}$ after $48 \mathrm{~h}$ (Table 1 ). Similarly, we had performed time-dependent analysis of caffeic-acid-treated cells. It also showed an increasing sub- $\mathrm{G}_{1}$ arrest from $1.75 \%$ (control) to $25.27 \%$ after $48 \mathrm{~h}$ (Table 2 ).

3.5. ROS Generation. ROS generation is involved in the apoptosis of many anticancer agents. Here, we examined the alteration in the ROS levels of caffeic-acid-treated cells. We had found significant increase in the ROS levels after caffeic acid treatment. The increasing mean fluorescent intensity was found to be 6322, 8309 during 24 and 48 h, respectively. Untreated control cells showed an intensity of 5441 after $48 \mathrm{~h}$ (Figure 3(a)).

3.6. Mitochondrial Membrane Potential. Mitochondrial membrane potential was found to decrease in caffeic-acidtreated cells. The decreasing mean fluorescent intensity was found to be 834,807 , and 774 during 6,12 , and $24 \mathrm{~h}$ of treatment, respectively. Untreated control cells showed an intensity of 1155 after $24 \mathrm{~h}$ (Figure 3(b)).

3.7. Yo-Pro-1 Staining. Apoptosis was assessed using YOPRO-1 staining by flow cytometry. The percentage of cells distributed in M2 population signifying apoptosis increased depending upon the dose and duration of treatment. Dosedependent analysis of 500, 1000, and $2000 \mu \mathrm{M}$ of caffeic acid showed an increasing M2 phase of 21.85, 30.06, and 39.01, respectively. Further, in time-dependent analysis, CA-treated cells showed increasing M2 phase population. It was found 

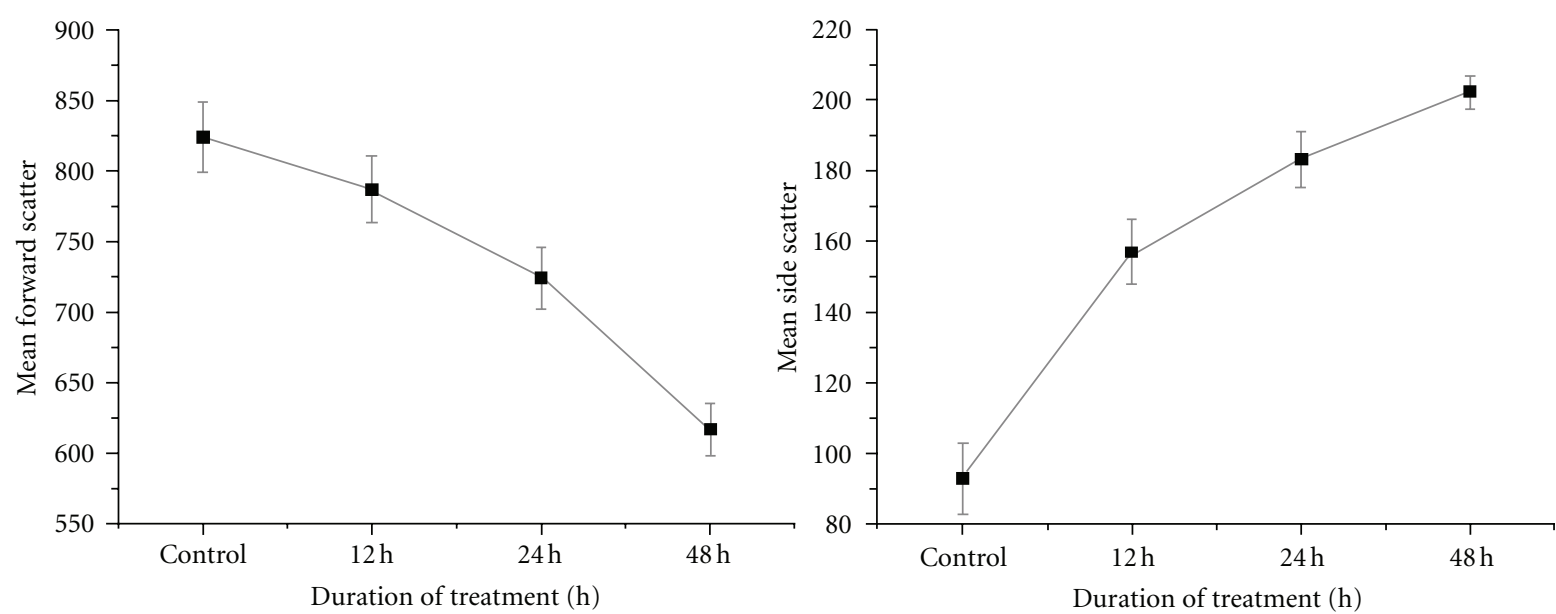

(a)
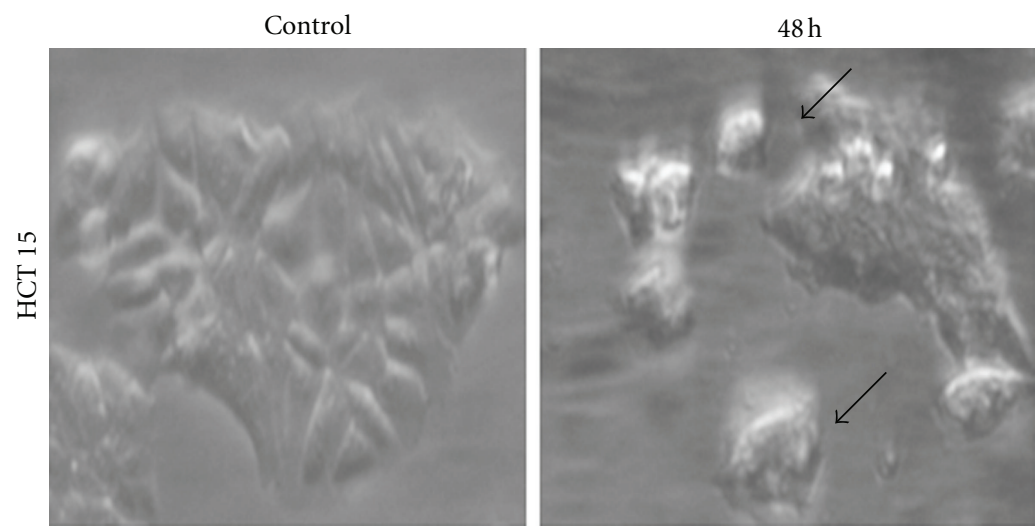

(b)

FIGURE 2: Changes to cell size and granularity distribution of caffeic-acid-treated cells. (a) Flow cytometric determination of cell forward and side laser light scatter was used to determine the relative changes to cellular size and granularity of HCT 15 cells after 12, 24, and $48 \mathrm{~h}$ of caffeic acid treatment. Data are mean \pm S.E from the three independent experiments. (b) Photomicrograph of caffeic-acid-treated cells was acquired along with the untreated control cells after $48 \mathrm{~h}$. Treated cells showed shrinkage compared to the normal cells as shown by arrow mark.

TABLE 1: Dose response of HCT 15 cells after caffeic acid treatment among various cell-cycle stages.

\begin{tabular}{lcccc}
\hline Dose $(48 \mathrm{~h})$ & Sub $\mathrm{G}_{1}^{*}$ & $\mathrm{G}_{0} / \mathrm{G}_{1}$ & $\mathrm{~S}$ & $\mathrm{G}_{2} / \mathrm{M}$ \\
\hline Control & $01.71 \pm 3.10$ & $27.31 \pm 4.57$ & $28.93 \pm 1.71$ & $39.72 \pm 2.15$ \\
$500 \mu \mathrm{M}$ & $11.61 \pm 2.78$ & $19.81 \pm 3.06$ & $29.88 \pm 2.58$ & $37.66 \pm 1.77$ \\
$1000 \mu \mathrm{M}$ & $26.27 \pm 1.08$ & $15.89 \pm 1.98$ & $20.45 \pm 4.21$ & $35.76 \pm 2.32$ \\
$2000 \mu \mathrm{M}$ & $33.10 \pm 2.23$ & $14.27 \pm 3.37$ & $19.34 \pm 1.30$ & $30.70 \pm 2.60$ \\
\hline
\end{tabular}

Data represents mean \pm S.D; $*$ means are significant at $P<0.05$.

TABLE 2: Time response of HCT 15 cells after caffeic acid treatment among various cell-cycle stages.

\begin{tabular}{|c|c|c|c|c|}
\hline Time in hours & Sub $G_{1}^{*}$ & $\mathrm{G}_{0} / \mathrm{G}_{1}$ & $\mathrm{~S}$ & $\mathrm{G}_{2} / \mathrm{M}$ \\
\hline Control (untreated, $48 \mathrm{~h}$ ) & $01.75 \pm 2.75$ & $26.84 \pm 3.98$ & $32.64 \pm 1.23$ & $36.51 \pm 1.72$ \\
\hline $12 \mathrm{~h}$ & $04.17 \pm 1.83$ & $38.90 \pm 4.15$ & $22.82 \pm 3.29$ & $32.57 \pm 3.87$ \\
\hline $24 \mathrm{~h}$ & $13.74 \pm 1.52$ & $25.04 \pm 3.26$ & $21.73 \pm 1.78$ & $38.13 \pm 3.12$ \\
\hline $48 \mathrm{~h}$ & $25.27 \pm 3.01$ & $19.54 \pm 4.39$ & $19.65 \pm 3.76$ & $33.71 \pm 2.90$ \\
\hline
\end{tabular}

Data represents mean \pm S.D; ${ }^{*}$ means are significant at $P<0.05$. 


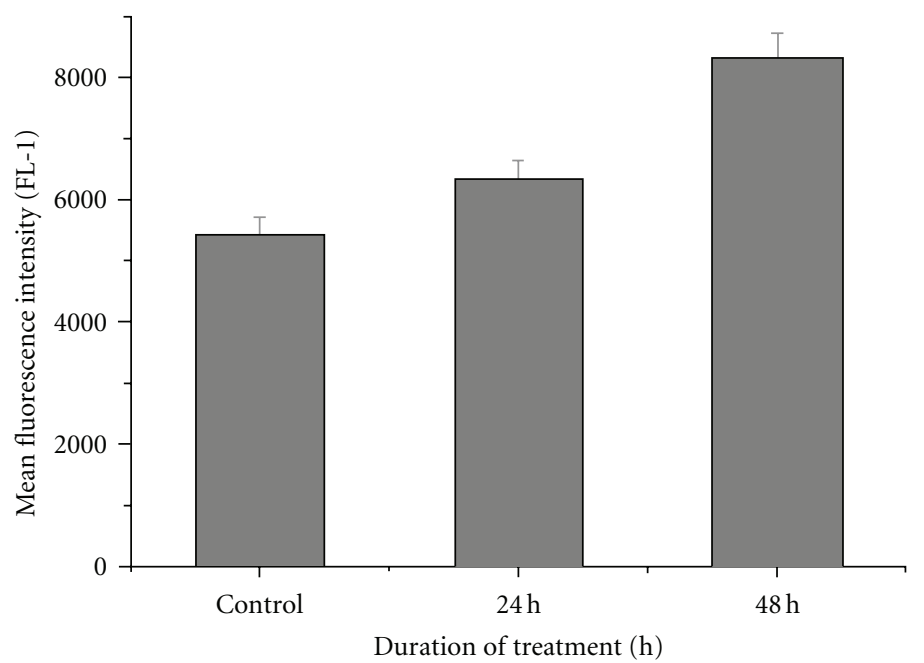

(a)

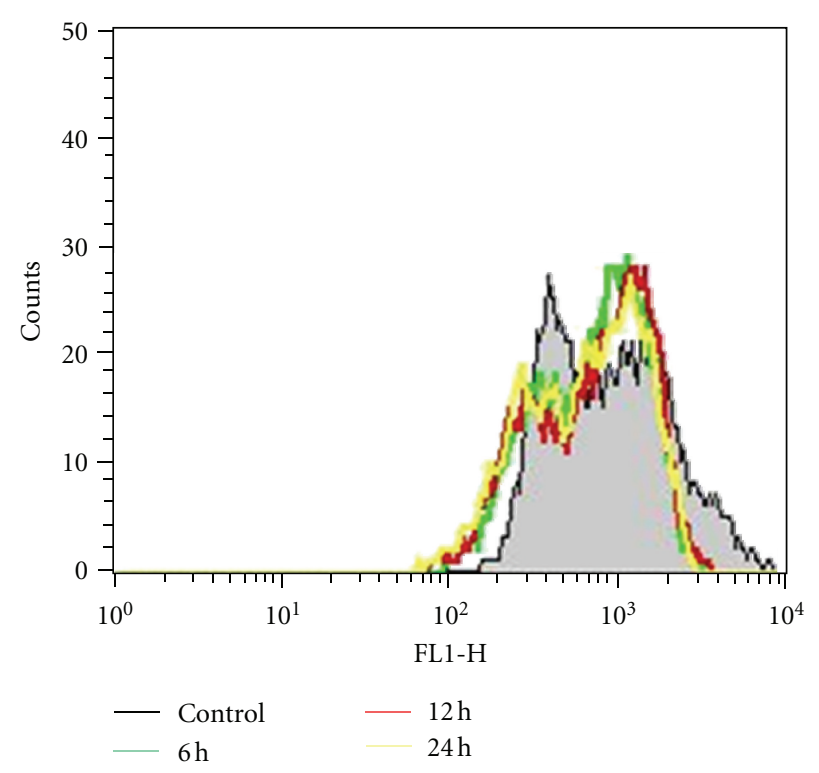

(b)

FIGURE 3: ROS generation and mitochondrial membrane potentials ( $\left.\Psi_{\mathrm{m}}\right)$ of caffeic-acid-treated cells. (a) HCT 15 cells were cultured in the presence or absence of caffeic acid for the specified time points. DCFDH-DA fluorescence intensity was detected by using flow cytometry. Data shows the mean and standard error of three independent experiments. (b) HCT 15 cells were treated with caffeic acid for specified timeperiods and then $\Psi_{\mathrm{m}}$ were determined using rhodamine 123 by flow cytometry. Data is representative of three independent experiments.

to be $13,16.78$, and 25.42 after 12,24 , and 48 h of caffeic acid treatment. M2 phase population of untreated control cells was found to be $8.62 \%$ after $48 \mathrm{~h}$ (Figure 4 ).

\section{Discussion}

Caffeic acid, one of the phenolic constituents of honey, significantly inhibited HCT 15 colon cancer cell proliferation. This result was in agreement with the previously published research which also showed inhibitory activity of caffeic acid against HT 29 colon cancer cells [10]. Colony-forming ability of cancer cells is essential for survival. Caffeic acid was found to inhibit the colony formation similar to some anticancer agent like Triphala (TPL), an Indian Ayurvedic formulation with known anticancer properties [14].

Selective killing of cancer cells using therapeutics is in constant demand for cancer. For this, targeting specific molecule using anticancer agents became the task, but problems like mutation and overexpression of the molecule make the task unfinished. Hence, better solution would be targeting specific biochemical reactions taking place inside the cell. One such thing is ROS, which plays a key role in various biochemical processes like apoptosis and cell proliferation. ROS stimulates the cell growth and proliferation hence increase in ROS is important in maintaining the cancer cell phenotype. However, high levels of ROS can also cause cellular damage, depending on the levels and duration of ROS stress $[15,16]$. Hence, by exploiting these time- and dose-dependent ROS generation, we can trigger cell death by using exogenous ROS-generating agents. In our case, caffeic acid was found to increase the ROS generation in the colon cancer cells as shown by DCFDH-DA staining. Moreover, confocal images of DCFDH-DA staining also corroborated the increasing ROS generation in the caffeic-acid-treated cells (data not shown). Hence, caffeic acid may be overlooked as a potential exogenous candidate (generating ROS) to induce apoptosis in colon cancer cells.

Mitochondrial membrane potential also plays a major role in the regulation of physiological cell death (apoptosis) of animal cells [12]. There will be reduction in the cellular uptake of mitochondrial membrane potential sensitive dye like rhodamine123 while animal cells undergoing apoptosis. A fall in the $\Psi_{\mathrm{m}}$ will constitute an event in the apoptosis of many anticancer drugs $[17,18]$. In caffeic-acid-induced apoptosis, we could evidence similar $\Psi_{\mathrm{m}}$ fall depicting that ROS-mediated apoptosis also accompanies mitochondrial dysfunction. This is greatly confirming with the results reported recently, where honey rich in phenolic content was also found to induce apoptosis by mitochondrial dysfunction [13]. Likewise, we hypothesize that the fall in the mitochondrial membrane potential and increased ROS generation may result in the activation of $\mathrm{p} 53$ in the caffeic-acid-treated cells. This may in turn, would have caused the upregulation of $\mathrm{Bax}$ and downregulation of $\mathrm{Bcl}_{2}$ which are the downstream targets of p53 resulting in apoptosis. Hence, it would be appropriate to perform Western blot of the above-said proteins in the future research.

The hall mark of apoptosis is membrane blebbing and DNA fragmentation. Literatures stated that electron microscopic image is the golden standard for detecting apoptosis $[19,20]$. Photomicrograph images clearly depicted the membrane blebbing and shrinkage. In this research, we showed that caffeic acid could arrest the cell cycle at the sub$\mathrm{G}_{1}$ phase (an indicator of apoptosis) both in a dose- and 

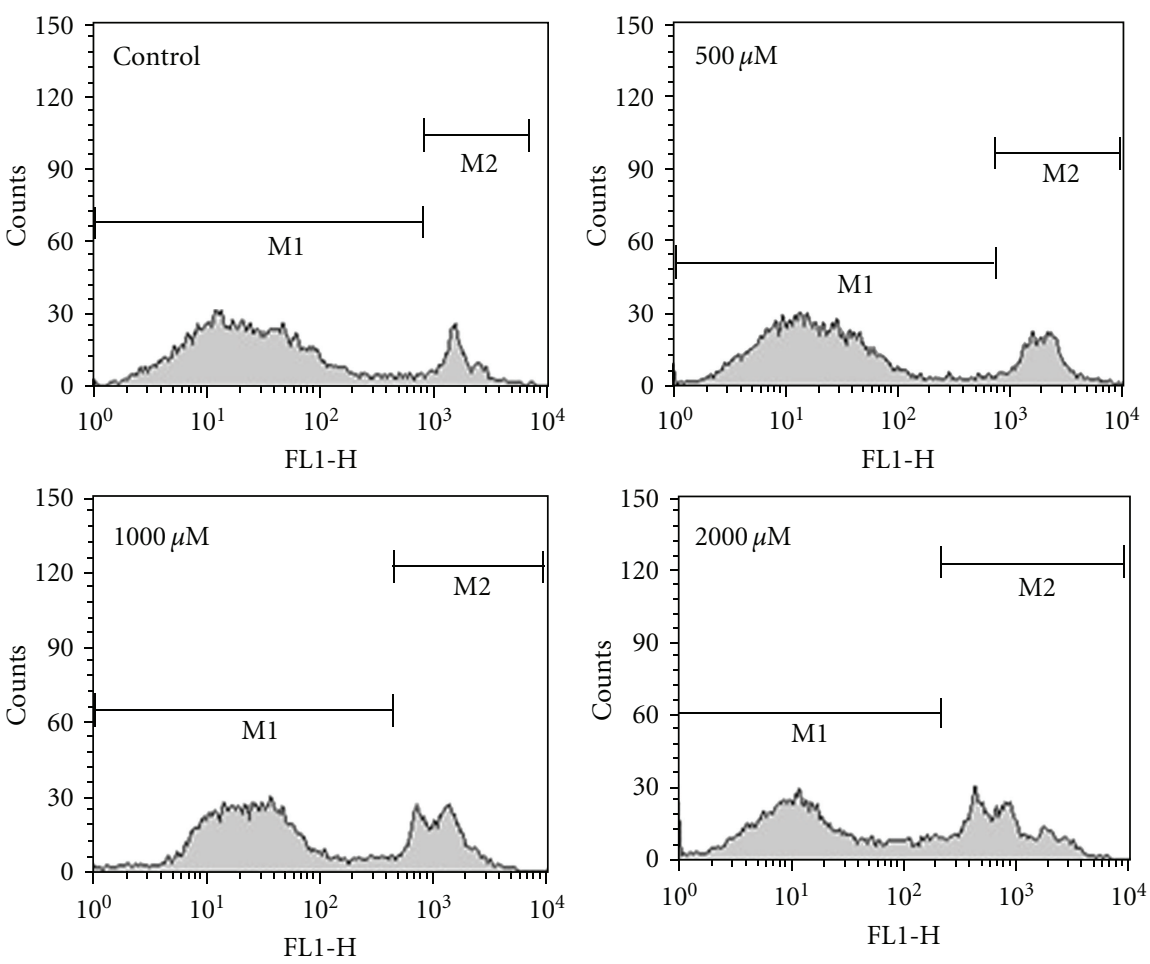

(a)
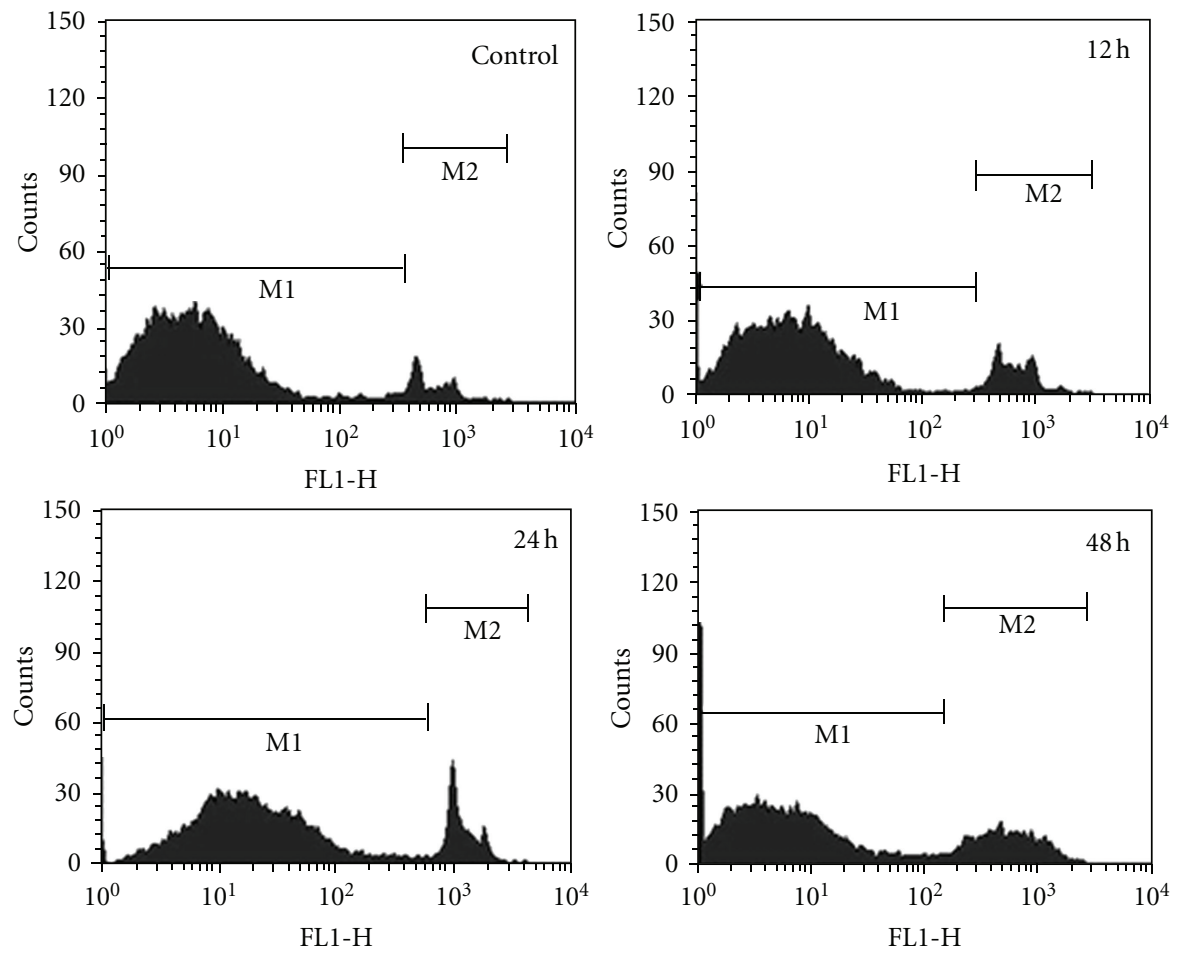

(b)

FIgURe 4: Apoptosis evaluation using Yo-Pro-1 dye by flow cytometry. (a) HCT 15 cells were treated with different doses of caffeic acid for $48 \mathrm{~h}$. The distribution of cell population changed according to the doses as indicated by M1 and M2. Percentage of M2 population depicting apoptosis increased depending upon the increasing dose. Data is representative of three independent experiments. (b) HCT 15 cells were treated with caffeic acid for specified time points. The distribution of cell population changed according to the exposure time as indicated by M1 and M2. Percentage of M2 population depicting apoptosis increased on the basis of the duration of treatment. Data is representative of three independent experiments. 
time-dependent fashion using propidium iodide staining. This was similar to the effect of caffeic acid phenethyl esters (CAPEs) against C6 glioma cells [21]. Further, confocal images of the treated cells showed distinct DNA fragmentation (data not shown). Yo-pro-1 is widely used to detect apoptosis induced by anticancer agents [13]. Dose- and timedependent staining by Yo-pro-1 demonstrated increasing accumulation of apoptotic cells after caffeic acid treatment. Induction of apoptosis was further substantiated by reduced forward and increased side scatter of the treated cells.

\section{Conclusion}

Caffeic acid, one of the phenolic constituents of honey, inhibited the colon cancer cell proliferation in a dose-dependent manner. Caffeic acid treatment resulted in increasing accumulation of cells at sub- $\mathrm{G}_{1}$ phase of cell cycle indicating apoptosis. Induction of apoptosis was accompanied by increased ROS generation as indicated by DCFDH-DA staining. Further mitochondrial membrane potential fall was also observed in the treated cells. Dose- and timedependent staining by Yo-pro-1 demonstrated increasing accumulation of apoptotic cells after caffeic acid treatment. Photomicrograph images depicted the membrane blebbing and shrinkage of treated cells. Hence, caffeic acid can be considered as a potential candidate for inducing apoptosis in colon cancer cells through ROS and mitochondrial mediated mechanism. However, further experiments in preclinical and clinical settings will promote this as a likely candidate for chemoprevention of colon cancer.

\section{Conflict of Interests}

The author does not have any conflict of interests.

\section{Acknowledgments}

S. K. Jaganathan acknowledges the directors' (Mr. Raguram, Dr. Lakshmana Prabhu, and Mr. Sugumaran) invaluable support and their constant encouragement. He acknowledges the efforts of Ms. Bhuvaneswari S for checking this paper.

\section{References}

[1] American cancer society, 2009, http://www.cancer.org/ Cancer/ColonandRectumCancer/DetailedGuide/colorectalcancer-key-statistics.

[2] S. K. Jaganathan and M. Mahitosh, "Honey constituents and its apoptotic effect in colon cancer cells," Journal of Apiproduct and Apimedical Science, vol. 1, pp. 29-36, 2009.

[3] S. K. Jaganathan, S. M. Mandal, S. K. Jana, S. Das, and M. Mandal, "Studies on the phenolic profiling, anti-oxidant and cytotoxic activity of Indian honey: in vitro evaluation," Natural Product Research, vol. 24, no. 14, pp. 1295-1306, 2010.

[4] F. Shahidi and M. Naczk, Food Phenolics. Sources, Chemistry, Effects, Applications, Technomic Publishing Company, Lancaster, UK, 1995.
[5] O. Vieira, J. Laranjinha, V. Madeira, and L. Almeida, "Cholesteryl ester hydroperoxide formation in myoglobin-catalyzed low density lipoprotein oxidation. Concerted antioxidant activity of caffeic and p-coumaric acids with ascorbate," Biochemical Pharmacology, vol. 55, no. 3, pp. 333-340, 1998.

[6] T. Tanaka, T. Kojima, T. Kawamori et al., "Inhibition of 4-nitroquinoline-1-oxide-induced rat tongue carcinogenesis by the naturally occurring plant phenolics caffeic, ellagic, chlorogenic and ferulic acids," Carcinogenesis, vol. 14, no. 7, pp. 1321-1325, 1993.

[7] J. Neradil, R. Veselská, and J. Slanina, "UVC-protective effect of caffeic acid on normal and transformed human skin cells in vitro," Folia Biologica, vol. 49, no. 5, pp. 197-202, 2003.

[8] V. Staniforth, L. T. Chiu, and N. S. Yang, "Caffeic acid suppresses UVB radiation-induced expression of interleukin-10 and activation of mitogen-activated protein kinases in mouse," Carcinogenesis, vol. 27, no. 9, pp. 1803-1811, 2006.

[9] T. W. Chung, S. K. Moon, Y. C. Chang et al., "Novel and therapeutic effect of caffeic acid and caffeic acid phenyl ester on hepatocarcinoma cells: complete regression of hepatoma growth and metastasis by dual mechanism," The FASEB Journal, vol. 18, no. 14, pp. 1670-1681, 2004.

[10] C. V. Rao, D. Desai, B. Kaul, S. Amin, and B. S. Reddy, "Effect of caffeic acid esters on carcinogen-induced mutagenicity and human colon adenocarcinoma cell growth," ChemicoBiological Interactions, vol. 84, no. 3, pp. 277-290, 1992.

[11] W. C. Earnshaw, "Nuclear changes in apoptosis," Current Opinion in Cell Biology, vol. 7, no. 3, pp. 337-343, 1995.

[12] H. Lee and Y. Wei, "Mitochondrial role in life and death of the cell," Journal of Biomedical Science, vol. 7, pp. 2-15, 2000.

[13] S. K. Jaganathan and M. Mandal, "Involvement of non-protein thiols, mitochondrial dysfunction, reactive oxygen species and p53 in honey-induced apoptosis," Investigational New Drugs, vol. 28, no. 5, pp. 624-633, 2010.

[14] T. Sandhya and K. P. Mishra, "Cytotoxic response of breast cancer cell lines, MCF 7 and T $47 \mathrm{D}$ to triphala and its modification by antioxidants," Cancer Letters, vol. 238, no. 2, pp. 304-313, 2006.

[15] D. Trachootham, Y. Zhou, H. Zhang et al., "Selective killing of oncogenically transformed cells through a ROS-mediated mechanism by $\beta$-phenylethyl isothiocyanate," Cancer Cell, vol. 10, no. 3, pp. 241-252, 2006.

[16] H. Pelicano, D. Carney, and P. Huang, "ROS stress in cancer cells and therapeutic implications," Drug Resistance Updates, vol. 7, no. 2, pp. 97-110, 2004.

[17] J. Liu, H. M. Shen, and C. N. Ong, "Role of intracellular thiol depletion, mitochondrial dysfunction and reactive oxygen species in Salvia Miltiorrhiza-induced apoptosis in human hepatoma HepG2 cells," Life Sciences, vol. 69, no. 16, pp. 18331850, 2001.

[18] Z. Siyuan, N. O. Choon, and M. S. Han, "Critical roles of intracellular thiols and calcium in parthenolide-induced apoptosis in human colorectal cancer cells," Cancer Letters, vol. 208, no. 2, pp. 143-153, 2004.

[19] H. S. Samaha, E. Asher, C. M. Payne, C. Bernstein, and H. Bernstein, "Evaluation of cell death in EBV-transformed lymphocytes using agarose gel electrophoresis, light microscopy and electron microscopy. I. Induction of classic apoptosis by the bile salt, sodium deoxycholate," Leukemia and Lymphoma, vol. 19, no. 1-2, pp. 95-105, 1995.

[20] D. Hockenbery, "Defining apoptosis," American Journal of Pathology, vol. 146, no. 1, pp. 16-19, 1995.

[21] Y. J. Lee, H. C. Kuo, C. Y. Chu, C. J. Wang, W. C. Lin, and T. $\mathrm{H}$. Tseng, "Involvement of tumor suppressor protein p53 and 
p38 MAPK in caffeic acid phenethyl ester-induced apoptosis of C6 glioma cells," Biochemical Pharmacology, vol. 66, no. 12, pp. 2281-2289, 2003. 


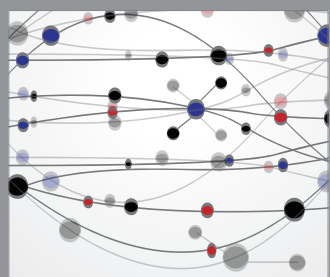

The Scientific World Journal
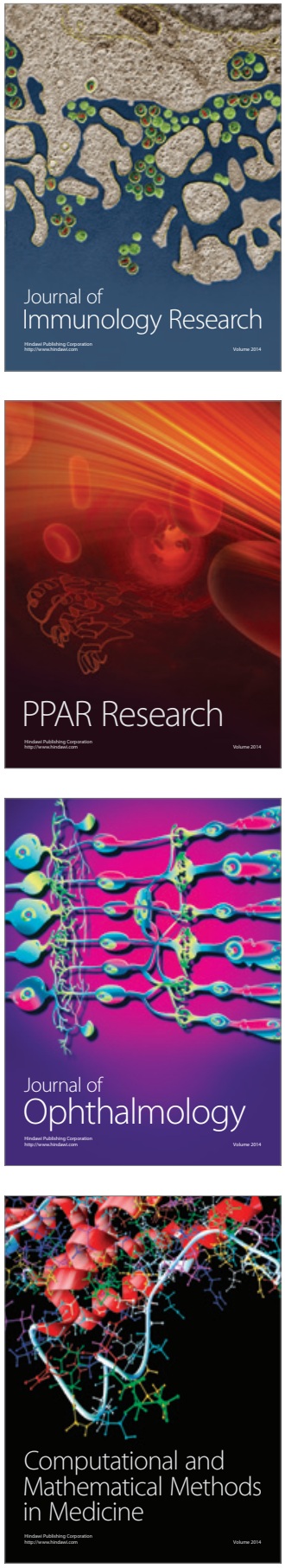

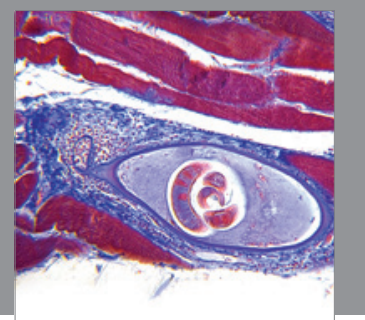

Gastroenterology

Research and Practice
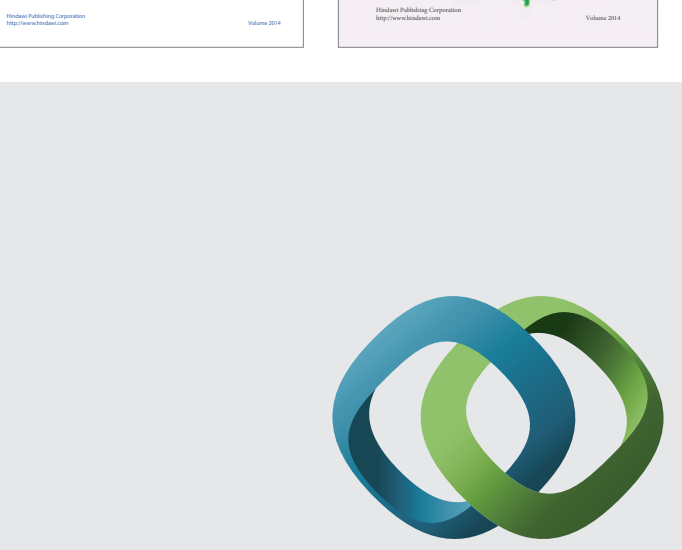

\section{Hindawi}

Submit your manuscripts at

http://www.hindawi.com
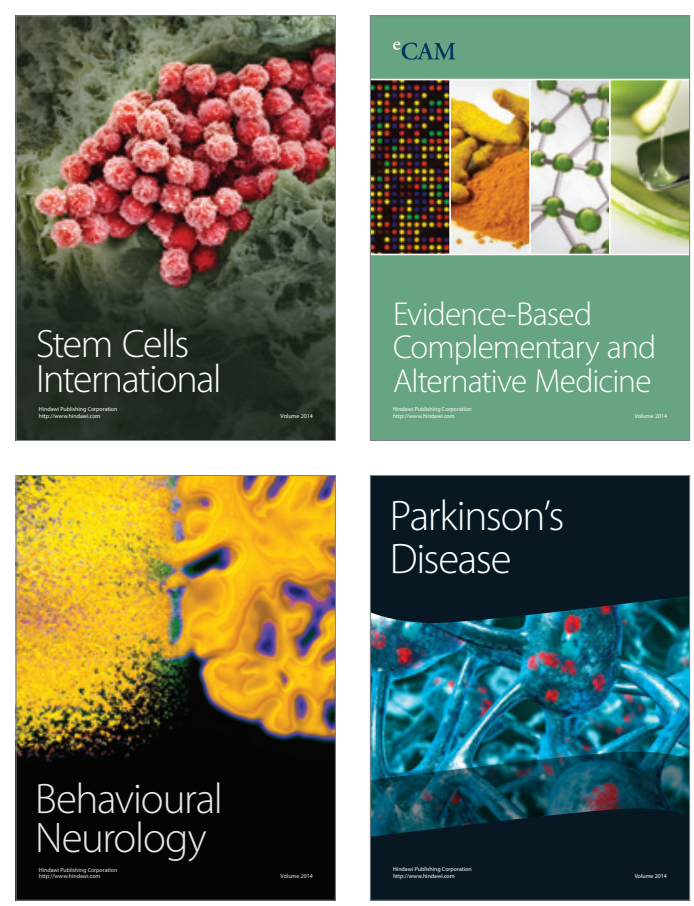

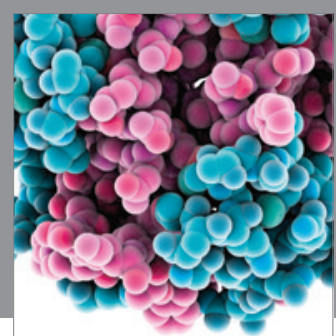

Journal of
Diabetes Research

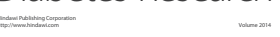

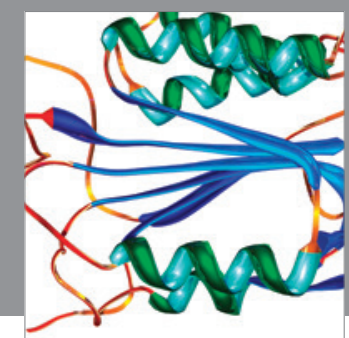

Disease Markers
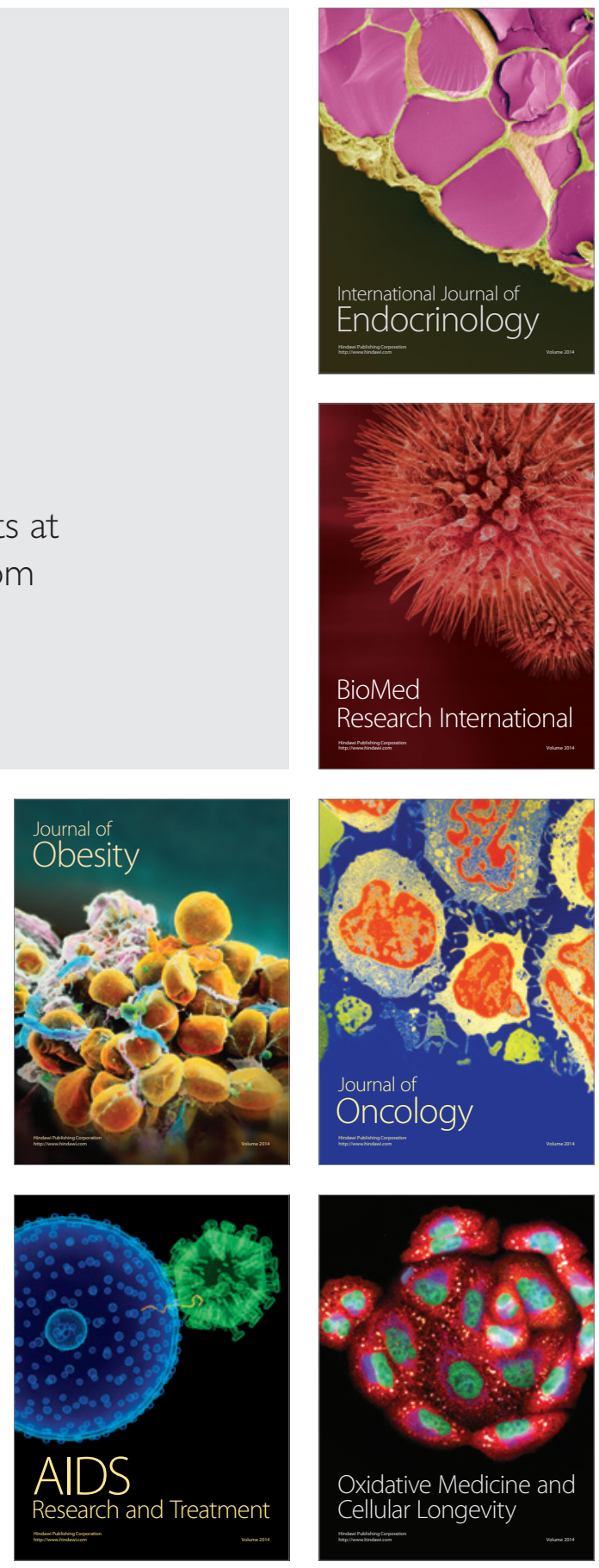